\title{
Los significantes de la narratividad en busca de una conciencia histórica en la poesía de Juan L. Ortiz
}

\section{Signifiers of narrativity in search of historical consciousness in the poetry of Juan L. Ortiz}

\section{Beatriz Vottero ${ }^{1}$}

Universidad Nacional de Villa María, Córdoba, Argentina

\section{RESUMEN}

El poeta argentino Juan Laurentino Ortiz es autor de una extensa obra en verso que revela su afición a los símbolos para desarrollar una poética de la esperanza en un contexto de injusticia social que hace necesaria una revolución. Desde una mirada hermenéutica nos aproximamos al extenso poema «Las colinas», sobre la hipótesis de que ese marco epocal aparece narrativizado desde una conciencia histórica. Trabajamos con la categoría de narratividad que propone Paul Ricoeur, así como con el concepto de mímesis, propuesto en Tiempo y narración, que posibilita no solamente la legibilidad de un discurso, sino su interpretación en la escala moral. De este modo, la lectura hermenéutica nos permite amalgamar la dimensión sociohistórica con la simbología de la refundación provocada por la conjunción de los cuatro elementos fundamentales: agua, fuego, aire y tierra en una acción política con significado de restauración ontológica.

\section{PALABRAS CLAVE}

Poética, revolución, conciencia histórica, hermenéutica

\section{ABSTRACT}

The argentine poet Juan Laurentino Ortiz is the author of an extensive work in verse that reveals his fondness to symbols for develop a poetic of hope in a context of social

1 Profesora y licenciada en Letras Modernas por la Universidad Nacional de Córdoba, Argentina. Especialista en Lectura, escritura y educación por la FLACSO-Argentina. Docente e investigadora en la carrera del Profesorado en Lengua y Literatura de la Universidad Nacional de Villa María, Córdoba, Argentina. Ha publicado numerosos artículos y ha dictado diversas conferencias y ponencias en encuentros académicos nacionales e internacionales. 
injustice which calls for a revolution. From a hermeneutical look we approach the long poem Las colinas (The hills), on the assumption that epochal framework is narrativized from a historical consciousness. We work with the category of narratividad proposed by Paul Ricoeur, as well as the concept of mimesis, proposed in Time and Narrative, which allows not only the readability of a speech, but his performance in the moral scale. Thus, hermeneutics reading allows us to amalgamate the socio- historical dimension with the symbolism of the refounding caused by the combination of the four basic elements: water, fire, air and soil, in a political action with meaning of ontological restoration.

\section{KEYWORDS}

Poetic, revolution, historical consciousness, hermeneutics

\section{Una lectura hermenéutica de la obra poética en clave narrativa}

El poeta argentino Juan Laurentino Ortiz desarrolló una vasta obra poética anclada en las imágenes de la cotidianeidad, donde la recurrencia al río y su contexto es, sin dudas, uno de los rasgos más representativos que la atraviesan. No se trata, sin embargo, de una obra paisajística, sino de una poesía fuertemente arraigada en la historicidad del sujeto, tan inserto en la circunstancia local como proyectado a la dimensión humana universal. Esta será, precisamente, la lectura que intentaremos al escoger uno de sus poemas paradigmáticos: «Las colinas», que pertenece al libro El alma y las colinas, de 1956. El texto se extiende en 992 versos y se inserta en el conjunto de poemas largos que habían comenzado a aparecer en El álamo y el viento, de 1947.

En este sentido, la mirada hermenéutica orientará nuestro trabajo de intérprete hacia el intento de comprender un contexto epocal, en la medida en que este aparece narrativizado desde una conciencia histórica. Es desde esta plataforma que hipotetizamos que la producción poética de Ortiz puede leerse como un extenso relato y, por lo tanto, explorarse desde la condición de narratividad que propone Paul Ricoeur, amalgamando la filosofía reflexiva, la hermenéutica y la fenomenología.

Si valoramos el texto poético, en este caso, como un texto narrativo, es posible observar que el proceso de enunciación implica, como propone Ricoeur, «llevar al lenguaje una experiencia, un modo de vivir y de estar en el mundo que lo precede y pide ser dicho» (2001, p. 35). Sería muy delicado, por otro lado, aplicarle a la poesía el carácter de texto ficcional, 
naturalmente propio del relato literario. No nos proponemos, entonces, leer el poema como narración, sino, valiéndonos en particular de la diferenciación propuesta por Gérard Genette (1989), sí como relato que comporta una historia, sumando de esta manera aportes de la narratología posestructuralista a la línea vertebral que sustenta nuestra lectura.

Como es sabido, para el filósofo y antropólogo francés Paul Ricoeur, la hermenéutica se injerta en el método fenomenológico. En este sentido, el enfoque elegido nos permite ir hacia el texto en busca de los contenidos de conciencia que aparecen a través de la palabra dada, sabiendo incluso que enfrentamos un ejercicio en el que nuestra propia persona quedará comprometida, como «intérprete interpretado» (según el propio Ricoeur), en tanto el relato constituye un modo de conocimiento que incluye el proceso de lectura (o refiguración del texto por parte del lector).

De allí también que nuestro interés por el tratamiento que Ortiz hace del lenguaje - que bien podría definirse como un trabajo de filigrana, finísimo - no se asienta en paradigmas lingüísticos en la medida en que Ricoeur los objeta para el estudio del relato, sino en la búsqueda de la imagen. En este sentido podemos afirmar que el sema río y la sugerente dinámica que provee al poema como paso del tiempo hace posible que todos los elementos, a partir del propio «movimiento» de las colinas, actúen como materia fundante de un ars poetica basada en la sucesividad que hace posible el relato. Ello significa que el Gran Río (la Mesopotamia argentina, formada por tres provincias, se define entre los ríos Paraná y Uruguay) no sea necesariamente el tropo más referenciado, pero sí que su presencia como dador de sentido a la vida de la naturaleza y del hombre en ese determinado contexto, sustenta, de alguna manera, la génesis y el discurso (palabra que discurre) del poema.

Particularmente en Tiempo y narración (1995), Ricoeur propone la idea de que los géneros narrativos se han ido ramificando inagotablemente a lo largo de las culturas de las que somos herederos, lo que, en su opinión, provoca un corrimiento y reformulación de los géneros clásicos como la epopeya, el drama, el cuento y la novela. En esa diferenciación, Ricoeur (2000, p. 192) reconoce, sin embargo, una unidad funcional entre los múltiples modos y géneros narrativos, a la que se refiere de la siguiente manera: «el carácter común de la experiencia humana, señalado, articulado y aclarado por el acto de narrar en todas sus formas, es su carácter temporal. [...] Incluso cabe la posibilidad de que todo proceso temporal solo se reconozca como tal en la medida en que puede narrarse de un modo o de otro».

En este sentido, nos interesa acercarnos a la obra orticiana desde la categoría de mímesis, propuesta asimismo en Tiempo y narración, denominada prefiguración y entendida como la experiencia de la vida cotidiana en 
tanto estructura prenarrativa que exige una comprensión práctica de la red simbólica que enlaza a enunciador y enunciatario, y que asegura no solamente la legibilidad del discurso, sino su interpretación en la escala moral.

Para Irene Klein (2007, p. 81), «el verdadero valor de la narratividad se funda en la posibilidad que tiene un sujeto de representar y estructurar el mundo, es decir, de dar sentido a la realidad, tanto la factual de los hechos actuales, como la simbólica de la ficción. La narrativa recupera así el antiguo sentido de gnarus y gnosis, un modo de conocimiento que emerge de la acción y que no reposa solo en las historias que contamos a nuestros hijos o leemos en momentos de ocio, sino en la forma en que vivimos nuestra vida». En este sentido, se asocia a lo que Jerome Bruner describe como dos modalidades complementarias que ordenan la experiencia: narrar y argumentar (2002), que en el poema de Ortiz veremos amalgamadas de modo singular.

De acuerdo con este recorrido de lectura, podemos afirmar que, como cantor/narrador, Juan L. Ortiz reúne las tres condiciones que la Antigüedad consideró capitales en el arte del aedo: invención, memoria y canto. Estas cualidades se concebían en relación directa con la división de las musas: Melete, Mneme y Aoide. También los discípulos de Pitágoras aseguraban recibir de estas el eco de la armonía de las esferas y buscaban el secreto de la vida fundado en un principio de armonía cósmica, pasible de «auscultarse».

Esta actitud de escucha, como veremos, es propia del contador en la poesía orticiana. El propio Ortiz lo expresa con su sencillez inconfundible: «la poesía es narración [...] de ciertos estados íntimos, siempre fue narración» (Dujovne Ortiz, 1978). Juan José Saer, por su parte, en la «Liminar» de la Obra completa, asegura que «el deseo [de Juan L. Ortiz] de conocer cada vez mejor su propio instrumento para utilizarlo con mayor eficacia, esa disciplina a la que únicamente los grandes artistas se someten, tenía como objetivo el tratamiento de un tema mayor, del que toda la obra es una serie de variaciones: el dolor, histórico o metafísico, que perturba la contemplación y el goce de la belleza que para la poesía de Juan es la condición primera del mundo. El mal corrompe la presencia radiante de las cosas y cuando sus causas son históricas sus efectos perturbadores se multiplican. La lírica de Juan recibe, en ondas constantes de desarmonía, los sacudimientos que vienen del exterior, y su respuesta es la complejidad narrativa de sus obras mayores, en las que esos sacudimientos son incorporados como el reverso oscuro de la contemplación. $Y$ el objeto principal de la contemplación, lo que engloba la multiplicidad del mundo, es el paisaje» (Saer, 1996, pp. 15-16). 


\section{Las colinas}

Su estructura primera es sencilla. Comienza describiendo los atributos del sujeto que le da título: las colinas de la provincia de Entre Ríos, personalizándolas como niñas que danzan. Seguidamente las va describiendo según el curso de las estaciones y la transformación de su fisonomía, desde el mes de octubre hasta el mes de setiembre, completando un ciclo anual.

Se trata, sin embargo, de un eje cronológico no solo circular sino espiralado, donde se van insertando situaciones de causa-consecuencia cuya dimensión ética potencia el sentido final del poema, referidas a los pormenores de la vida del nativo (pescador, jornalero, hachero) y su explotación por parte de los potentados de la tierra.

De modo paralelo, exquisitamente entramado, aparecerá el tema/ sema de la esperanza, articulado en una isotopía que recorre gran parte del poema atravesando tropos como el canto, la fiesta, el coraje, la valentía, la resignación (en el sentido positivo de resignificar), el deseo, la necesidad, en una verdadera unio contrariorum que desembocará en un tercer eje que alcanza la proporción de discurso profético, referido al día de la instauración de la justicia social. Esta mirada nos permite comprender cómo en el poema se abrazan la oda y la elegía.

En cuanto a la simbólica de la esperanza que se construye sobre esa estética basada en el ciclo anual de las estaciones, iremos viendo que se expresa en el maridaje de estas con el accionar de los cuatro elementos considerados fundamentales: agua, aire, tierra, fuego.

Conforme con estos supuestos que articulan hombre y naturaleza, se puede advertir en la obra orticiana una doble perspectiva, que Gilbert Durand (1971, p. 118) define - con palabras de Ricoeur-como dos hermenéuticas: una arqueológica, que domina en todo el pasado biográfico, sociológico e incluso filogenético; y otra escatológica, llamada al orden esencial.

\section{La imagen dinamizada y dinamizadora se construye sobre la escucha}

De allí que la tarea de escucha se proyecte en doble dimensión: hacia los estados íntimos tanto como hacia los sucesos y la realidad exterior, entramados en un sentir que explora los sentidos últimos y el alcance moral de la existencia humana.

El poeta expresa acerca de su obra: «El tema serían las cosas naturales y no la naturaleza. Aunque por otro lado siento más el jardín como un acceso al más allá del jardín, a los horizontes, al infinito. Cualquier planta me sugiere la vida de relación que mantiene con su alrededor. Por ejemplo, la relación que hay entre la circulación de la savia y el canto de las aves, 
o la hoja que se mueve al ritmo del canto musical del pájaro. Esto es por un lado comprobación y por otro - o como lo mismo-imaginación. Y la poesía sería frente a todo esto la voz del nivel humano entretejida a todas estas relaciones. Nosotros creemos que el ritmo, "la voz", es totalmente nuestra, pero resulta que también es de afuera. Y nuestra seguridad está dependiendo de ese ritmo» (Kamenszain, 1973). Si el canto surge tras la actitud de escucha, se comprende que el poeta (relator) cante, según hemos propuesto y también como los minnesingers o los trovadores, por haber escuchado el quejido de sus hermanos; y que el pueblo mismo cante en la voz del (su) poeta.

No cabe duda de que, al auscultar permanentemente el paisaje con el que se sentía profundamente compenetrado, Juan L. Ortiz se dejaba llenar (la expresión es suya) por los sones de una perfecta sinfonía que lo trasladaba imaginariamente hacia el corazón de toda criatura. Él mismo lo expresa afirmando que «la música diluye los contornos para hacer sentir la unidad de lo viviente» (Kamenszain, 1973).

En el poema que nos ocupa, la primera impresión que el autor comunica se refiere, precisamente, al movimiento que le inspiran las colinas:

Veis esas niñas que en Octubre bajan rítmicamente como para mirar recién el río Paraná? (p. 113)²

La personalización de las colinas le proporciona la imagen justa que conviene al movimiento que transcribe, y contribuye a la invención del relato (nos referimos a la inventio en el sentido que le otorga la retórica clásica, como lo que se sabe acerca de y en torno a).

De un río a otro han danzado las niñas hasta Diciembre con todas las sedas de la luz o de la penumbra o de la sombra,

—Oh, el sueño de su baile de ceniza bajo un rocío sin edad... (p. 115)

La imagen de baile remite directamente a la edad juvenil, casi pueril aún, por el apelativo «niñas». Y se completa con todas las ideas afines que convergen al símbolo: belleza, prestancia, salubridad, frescura, fecundidad, vitalidad, destreza para la danza:

Celestemente sensibles de lino y pálidas de avena, con cabellos de maíz y pliegues de trigo, ellas llegaran... 
Hacia La Paz, subieran y bajaran, solo de sombra y aroma bajo los algarrobos y los espinillos y sobre sus propios pies de flores... (p. 116)

Ese movimiento ondulante le permite al autor trabajar con toda la riqueza sonora de la voz, valiéndose de las marcas que le permite la escritura (signos de exclamación y de interrogación, puntos suspensivos, corchetes, paréntesis, uso libre de los espacios en blanco sobre la página, etc.).

El verso largo, por su parte, que caracteriza esencialmente al poema entero, da la pauta de un ritmo más bien pausado, a veces algo moroso, correspondiente a la ondulación de las colinas y a la gravedad de los sucesos dolorosos que se irán mencionando/racontando. La necesidad de cesuras, además, provoca una moderación o fisura en la cadencia del habla:

Ay, las compañías por allí también, telarañas absolutas, con sus lores, y los obrajes no muy lejanos con sus cantinas como boas para las fatigas del hachero... (p. 127)

En ese diálogo, el cantor, vate, compositor, primero escucha para recién decir, como hacen los contadores de historias en las culturas rurales:

Un silencio cortés, extremadamente cortés, ante las cosas y los seres... Ellos debían aparecer con su vida secreta solo llamando al silencio, pero con cuidado infinito, ah, y con humildad infinita...

«Gualeguay» ${ }^{3}$

\section{La recurrencia al contraste y a la elipsis para decir la compleja realidad}

Ortiz trabaja en abundancia con las nominaciones opuestas, donde las variantes lexicales están relacionadas por antinomia. Ello nos permite inferir una lectura en el plano paradigmático según un esquema de oposiciones sobre el que se construye cierta monotonía o recurrencia en el poema (repeticiones, fórmulas), tal como sucede en el relato popular: la lucha entre el bien y el mal expresada en las variantes sombra/luz, muerte/vida, tristeza/alegría, que en muchos casos se resuelven hacia los finales de versos con construcciones adverbiales modales que las absorben (de allí la unio contrariorum que mencionáramos).

En la «Introducción» a En el aura del sauce, Hugo Gola (1970) comienza citando algunas palabras de Cesare Pavese de su ensayo «Tienen razón los literatos», a propósito de esta tónica orticiana que venimos observando: «Todo auténtico escritor es espléndidamente monótono en cuanto en sus

3 La brisa profunda. Obra completa, p. 455. 
páginas rige un molde al que acude, una ley formal de fantasía que transforma el más diverso material en figuras y situaciones que son casi siempre las mismas». Líneas más adelante afirma que Ortiz permanentemente va moldeando las figuras a su alcance «dando pruebas de una espléndida monotonía».

Otros recursos que colaboran en la construcción simétrica en el poema son el paralelismo y la anáfora. El resultado es un despliegue semántico de las posibilidades de la imagen.

de esos montes que velan en un principio todo su equilibrio, de esos espejos de agua para los acentos nativos, de esas arterias libres para las crecidas y su cielo original, de esos cabellos «de parque» para, con los árboles, su humus, contra esa muerte pajiza, rasgada, o traidoramente leve (p. 129)

El encastre paralelístico muestra, a su vez, un pensamiento audaz, capaz de tejer, como afirma el mismo Hugo Gola, «una red de palabras, delicada y precisa, aunque aérea, semejante a esas inmensas construcciones que las arañas pacientemente entrelazan» (1970). Así el poeta crea un sistema donde unas imágenes interpretan a otras, como fuentes o como datos, sustantivos o potenciales, dando forma a un universo integrado, encriptado en el entramado simbólico y bajo la cosmovisión del Uno en la diversidad.

En este sentido, no podemos dejar de destacar el empleo incesante de los puntos suspensivos. Podría decirse que en Ortiz marcan un estilo. Por ejemplo:

Pero las niñas eran las mismas vidas de la orilla y así en Montiel sufrían con los pastos y los espinillos y el ganado y los hombres...

esa vaga amenaza que los volvía de otro mundo...

Y la «ilusión», ay, ahora cruel, era el frío oscuro de las tarde que corría por todo un escalofrío sin engaño... y las cosas y los seres se sentían traspasados por una noche larga... y eran hojas, solo débiles hojas, en la noche... (pp. 133-134)

Podríamos decir que se trata de un tratamiento particular de la elipsis: no solo omite palabras o partes de la oración que completan su sintaxis, sino que abre posibilidades al silencio dentro del poema. El narrador oral logra ese efecto en su público.

Los puntos suspensivos también motivan a percibir que el poeta está buscando la palabra, intentando pronunciar sigilosamente lo que es tan 
visible y a la vez tan complejo. En este sentido, podemos decir que el contador de historias (de la historia de su pueblo) balbucea, va probando, saboreando las palabras mientras las va encastrando en el discurso.

Este estilo aparentemente impreciso, por momentos casi pueril, de nominar la naturaleza, nos sugiere que la poesía de Juan L. Ortiz adopta el tono de un sencillo coloquio, sostenido con toda claridad en la relación dialógica que establece a través de la apelación directa al oyente. Esa conversación versa sobre todas las cosas que ocupan y preocupan a Juanele. Es, por lo tanto, un diálogo fraterno y confidencial, íntimo y elocuente. Un relato casi de entrecasa que surge de la necesidad de contar (en su doble sentido: relatar la secuencia de los hechos y sumar, nombrar cada elemento en el proceso de adición, poner en valor).

En ese trabajo de cuentería, el relator amalgama de modo transparente su mirada sobre el hombre y sobre la naturaleza, que - tal como hemos señalado - no es en la poesía orticiana simplemente un paisaje, y tampoco un mero contexto o un territorio donde suceden los hechos, sino más bien un locus sujeto a la acción humana que puede modificarlo, usarlo, cuidarlo, respetarlo, destruirlo, en la medida en que el devenir resulta precisa y necesariamente de esa conjunción.

Quizá quepa aclarar que no debemos confundir esta relación con la mirada romántica donde la naturaleza refleja el estado de ánimo del poeta o acompaña los acontecimientos que se narran. La relación dialéctica en este caso es intensiva, en el sentido de que los hechos no simplemente recaen sobre el entorno sino que hombre y naturaleza se resimbolizan mutuamente en un proceso de proyección de sentidos. Tampoco se podría rastrear en Ortiz una intencionalidad de ubicar al hombre como señor y amo de la naturaleza, según pretendía la filosofía cartesiana, o conforme la conocida jerarquización de los seres establecida por la tradición escolástica. Su relación con todas las cosas es una búsqueda permanente de lo que estas simbolizan en el universo uno y dinámico, mucho más cercana a una cosmología panteísta.

Ello se explica en la medida en que el poeta toma como referencia primera el paisaje local, pero logra nombrar una realidad que lo excede, gracias a la extensión semántica del símbolo. De este modo, como hemos propuesto, la palabra actúa como conciencia efectiva y es a la vez imposibilidad, susurro, rumor, silabeo.

Podríamos arriesgar, incluso, que en este sentido el propio poema, tan extenso, de verso libre y rima blanca que encuentran su cadencia según los tonos y los colores de la voz que dice, cuenta, nombra, denuncia, podría leerse «como un río» que fluye, en movimiento, por momentos 
dándose contra el arcillar y por momentos arrullado por los sauces, desvaneciéndose en las playas pasajeras, pasando a borbollones los estrechos entre las islas.

En resumen, podemos decir que Juan L. Ortiz desarrolla en su poema «Las colinas» un exquisito juego de contrapuntos.

\section{El ritmo de las estaciones y el avance del relato}

Trataremos ahora de profundizar en esa simetría que se construye en el poema sobre la imagen dinámica del ritmo ondulante del río, espejado en la visión de la ondulación de las colinas. Se trata de una percepción sinestésica que avanza/se transforma conforme el paso de las horas y el paso de las estaciones, y por ende también acorde avanza el relato, que se inscribe naturalmente en el tiempo.

El esquema, muy sencillo, sería el de una figura circular básica de concepción cuaternaria, según desglosaremos a continuación.

\section{La primavera, el agua}

La primera parte del poema corresponde a la primavera y celebra una naturaleza pródiga, en plena expansión, signada por la vitalidad que simboliza el agua:

Mas las niñas, en verdad, fueran la ubicua primavera, hacia arriba y hacia abajo, a la vez, por todos los lados de la brisa: unas se decidieran por las islas y las ganara el olvido:

leguas de encanto, por el sur, hasta el Rincón de Nogoyá, con los cariños viejos de una diosa profunda: el agua, y una seguida, seguida, revelación de almas lacustres, que parecían mojar, todavía más, fúnebremente, los atardeceres

$$
\text { perdidos... (p. 119) }
$$

La primavera es escenario propicio para la danza de las colinas/niñas que van recorriendo en sus movimientos los diferentes recovecos de los ríos y bañados de la Mesopotamia. Como hemos anticipado, en ese «paseo» ellas van siendo testigos y referentes de la realidad del hombre que asienta sus pies sobre la pródiga tierra de sus entrañas. En la sugestiva percepción que propone el poema, son ellas quienes recorren el paisaje, danzando y siguiendo el transcurso del agua.

\section{El verano, el fuego}

El verano es la segunda etapa del ciclo. Es el tiempo en que la fruta madura y se cosecha el cereal; sin embargo, sobreviene la sequía y -así como el agua signó la fecundidad primaveral - el fuego parece la marca del estío: 
Oh, el día es de armas sobre ellas, y solo en el alba y al anochecer y bajo las estrellas respiran en el hálito celeste o azul o gris perdido... Íntimas, sangrarán de la sangre lenta que vieran en los que en ellas creyeran prometidos a su dicha, cayendo de los ojos, de los brazos, y siendo la sombra misma de la vuelta, al bajarlas sin nada, sin nada, por la mañana y al crepúsculo? (p. 123)

\section{El otoño, el aire}

El otoño vendrá, en la tercera estación, a traer nuevamente la bendición del agua:

Y helas aquí en marzo, más bellas que jamás...

Niñas ligeramente graves al principio, sorprendidas por las tardes... Niñas después, que saben, pero que continúan danzando...

Niñas que asumen, condenadas, todas las despedidas, pero que miran más allá, más allá, con un celeste libre... Mas las Iluvias han llamado pupilas sin número y sin nombre entre las titilaciones maduras, como de tules, de las hierbas, y los tallos sutiles, sutilísimos, de cristal recién nacido...

Y su corazón mismo, en la media tarde, parecía de cristal... (p. 131)

Sin embargo, podemos alegar que su signo es el aire. El frescor del otoño, luego de un estío ardiente, parece devolver la vitalidad a las niñas exhaustas que, sin embargo, no se habían detenido, como no se detiene la vida en la naturaleza («No dejaban de danzar, no, en el verano, las niñas», p. 125). Por esa vitalidad el poeta habla del corazón de las colinas, imagen fundamental de actividad energética según un ritmo isocrónico que pone en marcha el bombeo de sangre, de vida.

De este modo la voz que enuncia y cuenta logra, por la metáfora, ofrecer la imagen precisa del «respiro» (apoyado por el ritmo sanguíneo) que el otoño procura a las niñas, refiriéndose al elemento natural aire. Los versos dan la impresión de que las colinas se insuflaran, casi flotaran, por efecto de la brisa o del viento:

y más allá, más allá, por todo el país, al atardecer, una de cosechas aéreas, ya celestes, que vencían a la noche... Y ellas, más sensibles aún, temblaban del vuelo de las hojas,

de la densidad que huía de los montes, de las viñas que morían de amor por Concordia y por Colón...

Pero a la vez un pensamiento como de agua clara parecía volverlas hacia sí, en un misterio quieto... (p. 133) 
Pero el otoño es también el tiempo de la inundación y de la consecuente muerte para los animales y para la gente pobre, anticipando el crudo invierno:

Mas la crueldad, casi de súbito, era aún el agua de esa noche: sucia, y lívida de rabia, quería ganar a los seres, y venía ya helada, helada, como la muerte de Junio. (p. 134)

\section{El invierno, la tierra}

Por fin, llega el invierno, la cuarta estación del ciclo, con su belleza particular que tiene, sin embargo, la crueldad de hacer sentir el frío en las casas más humildes, por lo que la misma belleza exterior se avergüenza:

Y era la helada misma, a veces, la que irradiaba de novias una danza de hondos tules y de hialinos ñandutíes que en movimientos irisados parecían buscar la selva en un aire de pudor...

deíntimopudor,también, porloquehabía decruelenesagracia...(p.146)

Sin embargo y paradójicamente, en especial en esta última parte del poema, la metáfora canaliza eficazmente una sutil esperanza que palpita en el seno de ese paisaje gris. Las imágenes están tratadas con el ajuste que caracteriza al poeta entrerriano (los cuadros difusos o polivalentes hacen referencia a una realidad percibida del mismo modo, por lo que resultan tan precisos), de tal manera que el invierno, mostrado en toda su crudeza, deja entrever su signo de vida latente que dará continuidad al ciclo en la próxima primavera. Por ello es el invierno, para Juanele, el tiempo de la esperanza, tema que desarrolla extensamente en este último tramo:

Mas eran la multitud pura, y eran el ardido amor en vela...

Y así las veía Julio llegar a su final,

transidas a veces de su misma luz, pero danzando, no dejando de danzar ni aún en la nieve invisible, y vueltas, vueltas, sobre todos los silencios humildes que ya no parecían vivir bajo una invocación solo, ay, de ramas...

Oh, ellas no estaban sordas de tanto oír crecer las hierbas,

y sentían, en dolorosas, todos los latidos inocentes crucificados por el frío... (pp. 152-153)

El invierno será, entonces, el tiempo signado por la tierra que guarda con «ardido amor en vela» el sueño, la esperanza de una restauración (en el sentido de recuperación de un estado previo pero también de reparación), de una nueva primavera: 
Y venía Agosto, y hacia la mitad, casi de súbito,

las nieblas aparecían niñas como ellas

con una dulzura hesitante entre las ramillas algo lilas.

Y era asimismo la línea de una melodía que se buscaba

en parecida medida a la de ellas, temblando...

Alma ligera en el aire, ya de ave,

hasta hacer el día, ya de ave, sobre el sueño de la tierra... (p. 153)

La imagen del ave es símbolo de la libertad, de la plenitud, de la expansión de las potencias de la vida. La poesía será el canto del día nuevo, el sueño hecho realidad, la expresión de un nuevo comienzo. Un gesto fundacional.

En síntesis, y conforme nuestra interpretación del relato en el marco de la mirada elegida como campo teórico, el ciclo de las cuatro estaciones se corresponde con los cuatro elementos considerados fundamentales por los antiguos, según el maridaje propuesto líneas arriba.

Sabemos que, prima facie, puede parecer una relación forzada, y de hecho no es taxativa sino más bien aleatoria, de manera que todos los elementos interactúan sin resultar excluyentes. Pero sostenemos que en «Las colinas» Ortiz delata una apreciación específica de agua, fuego, aire y tierra, que nos da lugar a suponer — como venimos remarcando-que no solo celebra la apariencia de los fenómenos, sino que está imbuido de lo que estos elementos, debidamente valorizados, simbolizan en el inconsciente colectivo de una comunidad inscrita en un tiempo y un espacio determinados.

Paul Ricoeur (2004), en Finitud y culpabilidad, asegura que cosmos y psique son dos polos de una misma expresividad, de modo tal que el sujeto explora su propia sacralidad descifrando la del universo, pero no yendo «tras» el símbolo, sino a partir de él, que es lo que le permite una visión ética del acontecer. Así, Juan L. Ortiz, al descifrar la sacralidad del mundo a través del simbolismo arcaico de los cuatro elementos, explora la de su pueblo, acoge su ontofanía. Para Gilbert Durand (1971), «agua, fuego, tierra y aire, con todos sus derivados poéticos, no son sino el lugar más común del imperio en que lo imaginario se une directamente con la sensación» (p. 83).

Gaston Bachelard (1953, 1958, 1982), por su parte, propone recurrentemente que en la naturaleza no todos los aspectos son igualmente reveladores. Las líneas, las formas y los colores se corresponden con zonas racionalizadas del psiquismo, por lo que, también para él, el sustrato del yo encuentra su homólogo en los cuatro elementos que la física antigua, arraigada en la imaginación colectiva, señala como constitutivos de la materia. 
Por otro lado, los elementos no solo tienen relación con las cuatro estaciones del ciclo anual. Las antiguas nociones alquimistas señalaban una conexión directa entre estos y las denominadas cuatro etapas del ser sobre la tierra. La última de estas sería la del sujeto pensante, es decir, la del hombre (como fase superior desde el primer ser viviente unicelular). Este cuarto grado no señala, sin embargo, desde una perspectiva evolucionista basada en la filosofía de la naturaleza, que el estado actual sea el escalón óptimo de la vida. Por el contrario, la alquimia entiende una evolución siempre ascendente hacia una organización superior de la naturaleza y de la sociedad humana.

Quizá quepa aclarar que en el caso de Ortiz ese estado de gracia al que se aspira no debe entenderse en clave religiosa (en el sentido etimológico como religare, o regreso del hombre a Dios luego de la caída en el pecado), ya que en nuestro poeta la revolución tiene una base esencialmente materialista-histórica, apoyada, entre otras cosas, en su admiración por la cultura china y su adscripción a la teoría política de Mao y a las bases de la revolución del campesinado.

Sabemos, por otro lado, que Juan Laurentino Ortiz era un lector apasionado de las ciencias denominadas esotéricas y que descreía de la supremacía de las ciencias empíricas, sin negar por ello su representatividad de la época que vivimos. Preguntado en una entrevista, en 1975, sobre su pensamiento acerca de la modernidad científica, respondió: «Pienso que el proceso de industrialización está complicando enormemente las cosas, y esto es general. Ya sabemos en manos de quién están esos medios. Es muy peligroso. Así, los restos que todavía subsisten en nuestro país de esa cultura popular y rural no pueden manifestarse porque los medios masivos dictaminan otra cosa» (Zelarayán, 1975).

El optimismo de Ortiz deviene entonces de creer fervientemente en una revolución (en su sentido etimológico: revolutio, «vuelta, giro, regreso, circulación») y es así como entiende la evolución: de modo espiralado, como hemos remarcado. En otras palabras: se regresará al principio, pero sobre un escalón más alto. No es el eterno retorno de los griegos, la rueda de la fortuna. En el poema que trabajamos, su concepción de la evoluciónrevolución pude ilustrarse con los siguientes versos:

Sí, a la séptima vez, las viejas murallas caerán, «y el tiempo de las moradas más bellas que las catedrales vendrá...»

Pero no había en ellas uno como aire de evasión en su mismo movimiento hacia la perfección que les daba la música y a la que ellas dedicaban, a su vez, los pasos que iban creando? (p. 151) 
Encontramos aquí una referencia muy clara al episodio bíblico de la toma de Jericó por el pueblo hebreo, bajo el mando de Josué, luego del éxodo que los había conducido a la Tierra Prometida. Las murallas cayeron al sétimo rodeo de la ciudad por el poder del clamoreo rítmico, en hebreo Teru'ah, que designa un clamor religioso y guerrero que formaba parte de todo ritual, para lograr su eficacia (Josué 6, 1-20). El número siete simboliza la plenitud, es decir -en este caso- el cumplimiento de la promesa latente. La música, a su vez, como dadora de «movimiento hacia la perfección», señala el ritmo de un tiempo no meramente histórico o cronológico, sino permanente.

El rodeo, el retorno del movimiento circular in crescendo, provee la imagen simbólica de la espiral que da lugar a la ferviente esperanza del poeta, a pesar de que las pesadumbres se repitan.

\section{La esperanza en la revolución}

Arribamos, de esta manera, al sentido final que nuestra lectura nos viene proponiendo; no sin antes señalar que consideramos que el poeta recurre a los símbolos mencionados para explicar lo inexplicable o, mejor, lo inconcebible: la riqueza natural garantiza el alimento y el cobijo para todos, pero su distribución inequitativa deviene en injusticia. La esperanza, entonces, vale repetirlo, solo puede anclarse en la acción del hombre, a quien le cabe la responsabilidad de la revolución. En esa lucha, sin embargo, no está solo: su toma de conciencia y su decisión se asientan en la garantía de una permanente refundación provocada por la conjunción de los cuatro elementos. De este modo, ese estado edénico al que se aspira no es, para Ortiz, solo el resultado o consecuencia de una revolución, sino la revolución misma siempre en marcha, que se construye sobre el paso de las horas, aguardando y diseñando, cada día, la oportunidad para la acción política que significará la restauración ontológica. Expresaba en una entrevista que le hacía su amigo Vicente Zito Lema: «Por supuesto que la lucha humana, en ese sufrimiento social por las injusticias, nos toca más: el hombre es nuestra especie» (1975).

Hacia el final del poema, entonces, el repaso de los muchos pormenores que angustian cotidianamente la vida del pobre se prolonga en 35 versos que no olvidan a los ancianos, al yuyero, al tropillero, a las muchachas obligadas a trabajos pesados o desgarradas en su pudor, al peoncito, al pescador, al que agoniza a causa del hambre o de las enfermedades no atendidas debidamente.

De la ofrenda de todo ese dolor nace la figura del pueblo como héroe de la liberación: 
«El héroe de la acción común, que no requiere las grandes ocasiones

que exaltan comúnmente a los más bajos», ni está hecho «de ese poco de delirio, de ese poco de vanidad, de esa gran terquedad y de ese placer deportivo vulgar»,

como el de la veneración tradicional: silencioso y armónico lo mismo que un soldado desconocido...

Un héroe simple, sí, hecho de dominio de sí mismo, en la humilde verdad de un corazón que estrecha el infinito, sin embargo.

Y atento y sin miedo a ninguna vía de salvación porque viene del amor de los siglos y la salvación es la estrella...

Y es un héroe, ay, que llega de los mártires, «de los mártires que vivieron cien veces su propia muerte»,

pero que trae la victoria de los mártires, "como la paloma del arca, con una ramita que es un signo...» «Y es la suya una manera de ser hombre después de haber atravesado aun la noche de los túneles, llena de amenazas...» (p. 150)

Ortiz propone en estos versos el modelo de un hombre integrado, personalizado en un héroe colectivo o popular que no rehúye del dolor: «inclinado sobre las llagas profundas y los temores sin edad» porque ha pasado por «la noche» que condensa la experiencia de sentirse desamparado, oprimido, denigrado. Pero que desde las tinieblas es impulsado hacia la luz por la fuerza del deseo que reclama justicia: «y que no teme morir porque está "ligado al gran sueño de todos que no puede abortar"...» (p. 151).

Fiel a su alineación política y filosófica, remite a la cultura oriental:

Y más allá, lejanas, eran «las mil sonrisas de lo único», el cosquilleo infinito de Maya, la danza cósmica de Shiva...

Krishna llamando con su flauta a los múltiples destinos... (p. 151)

La danza de Shiva se refiere a la unión erótica de los elementos de la naturaleza, el sonido de flauta de Krishna representa el llamado del Tao a la paz en la unidad. La danza, la flauta y el canto son portadores del clamoreo restaurador de la integración ontológica, según predicaba el Tao: los seres y las cosas toman forma y surgen a la actividad, para volver nuevamente al reposo. Así cumplen un mandato:

Era, pues el juego primero de la Madre, la de la fábula, con las palabras nacidas de las cosas en una gran alma, y floreciendo unas en otras las cosas con nuevos pensamientos? ¿Era la sombra y la luz, ya, en una claridad inédita? 
¿Era la muerte y la vida, ya, en un amor desconocido?

¿Era la tristeza y la alegría, ya dándose la mano? (p. 154)

Por eso el pueblo hablará «con la fuerza de un poema»:

Mas con la poesía también como ángel natural del cielo de la ofrenda o de la infinita participación, sobre las voluntades imantadas

que hablarán a su vez con la dulce fuerza de un poema al hacerse ella carne, y latidos, y acciones, más allá de los pronombres... (p. 155)

Como Hölderlin y Novalis, Ortiz siente a la poesía como la reconquista de la inocencia. Es entonces el poeta, y no solo el pueblo como un colectivo, quien asume su posición de sujeto revolucionario: «La experiencia poética es una percepción, un sentimiento de ciertas zonas de la realidad que el conocimiento racional no abarca. La poesía es fundamentalmente descubrimiento. Esto no debe ser interpretado como que el poeta, que vive en una época determinada y está vinculado con los hombres y los hechos, no escucha la voz del pueblo, esa voz que le permite tener una esperanza en la revolución» (Kamenszain, 1973).

Como hemos apuntado, hacer la revolución significa dar un paso, lograr una modificación de cierto (des)orden dado, pero también representa un regressus (re-volutio): "Yo diría como Artaud o como Césaire que la poesía está unida ahora a la revolución. En el sentido de las transformaciones. Porque el poeta obra con el lenguaje mismo para apresar esa realidad que es muy fluida y confluyente y que es también contradictoria. Y debe asimismo modificar todas las convenciones comunes de la comunicación. Se está así frente a una revolución en el lenguaje que puede incidir después en otros planos de la transformación en tanto toca otros planos de la concepción de la realidad o de su percepción en los lectores u oyentes. No olvidemos que el hombre está en la prehistoria, no ha penetrado en la verdadera historia, y el poeta está comprometido en esa tarea» (Zito Lema, 1975).

En el poema que hemos elegido para este trabajo esa voz del pueblo está reclamando el cese de los atropellos y la recuperación del derecho a vivir en paz y en armonía con la naturaleza. Por eso, en la visión profética del autor, el día nuevo llegará con «la revolución por la delicadeza»:

¿No era ya la nueva conciencia en una unidad libe, de azucena, $y$, oh sorpresa de los tiempos, no se estaba ya en «la revolución por la delicadeza? (p. 156) 
«Acaso la revolución consista - declaró en otra oportunidad Juaneleen lo que el hombre por siglos ha estado postergando: la necesidad del verdadero descanso, el que permite ver cómo crecen, día a día, las florcitas salvajes... El hombre necesita mirar las flores y mirar el cielo...» (Zito Lema, 1975):

Aquel cielo accesible, al fin, abriendo con ellas, la ronda del gran día...

$$
\text { (p. 156) }
$$

Cerramos entonces este trabajo de aproximación a la densidad simbólica del poema «Las colinas», de Juan Laurentino Ortiz, con la voz del poeta en sus propios versos de infinito dolor y de infinita esperanza:

Pues de toda la vida, en fin, ellas morían... más serenas, eso sí, frente al molino de las agonías sin límites, porque sabían que otro canto, al cabo, iría ganando las tinieblas, con menos quejas cada vez, en el contrapunto más libre cada vez...

y los hijos de los hombres, sobre las disonancias y los miedos, serían los amos del juego infinito, tocando la unidad, y el torbellino de las estrellas, se volvería, por último, la rueca de sus días... (p. 125)

Espacios abiertos, hendiduras de la palabra poética que anuncian, como el propio símbolo, la emergencia de sentidos que convocan a ser explorados, recorriendo los versos y dejándonos llevar por la voz que denuncia porque canta. 


\section{REFERENCIAS BIBLIOGRÁFICAS}

Bachelard, G. (1953). El psicoanálisis del fuego. Buenos Aires: Schapire.

tura Económica. (1958). El aire y los sueños. México D. F.: Fondo de Cul-

de Cultura Económica.

(1982). La poética de la ensoñación. México D. F.: Fondo

Bruner, J. (2002). La fábrica de historias. Derecho, literatura, vida. Buenos Aires: Fondo de Cultura Económica.

Dujovne Ortiz, A. (domingo 16 de abril de 1978). El escondido licor de la tierra. La Opinión, suplemento cultural, pp. 1-4.

Durand, G. (1971). La imaginación simbólica. Buenos Aires: Amorrortu.

Genette, G. (1989). Figuras II. Barcelona: Lumen.

Kamenszain, T. (7 de junio de 1973). Juan L. Ortiz. Las arrugas son los ríos. Clarín.

Klein, I. (2007). La narración. Buenos Aires: Eudeba.

Ortiz, J. L. (1970). En el aura del sauce. Introducción de Hugo Gola. Rosario: Editorial Biblioteca.

del Litoral.

(1996). Obra completa. Santa Fe: Universidad Nacional

Ricoeur, P. (1995). Tiempo y narración. México D. F.: Siglo XXI.

Revista Analisi (25), 189-207.

(2000). Narratividad, fenomenología y hermenéutica. (2001). Del texto a la acción. Buenos Aires: Fondo de Cultura Económica.

(2004). Finitud y culpabilidad. Madrid: Trotta.

Saer, J. J. (1996). Liminar. En Juan L. Ortiz, Obra completa (pp. 15-16). Santa Fe: Universidad Nacional del Litoral.

Zelarayán, R. (20 de marzo 1975). Una cultura que en vez de liberar reprime. Entrevista a Juan L. Ortiz. Clarín.

Zito Lema, V. (27 de diciembre de 1975). Conversación con Juan L. Ortiz. El Cronista. 